\title{
Aposthia: A Congenitally Deficient Prepuce without Hypospadias
}

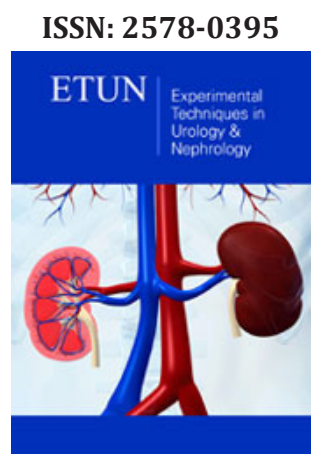

For HTML Version scan this QR code:

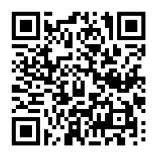

${ }^{* 1}$ Corresponding author: Gadelkareem RA, Assiut Urology and Nephrology Hospital, Assiut University, Assiut, Egypt. 71515; dr.rabeagad@yahoo.com

Submission: 眥 February 04, 2019

Published: 僵March 07, 2019

Volume 2 - Issue 5

How to cite this article: Gadelkareem R, Elgammal M. Aposthia: A Congenitally Deficient Prepuce without Hypospadias. Exp Tech Urol Nephrol. 2(5). ETUN.000547.2019.

DOI: 10.31031/ETUN.2019.02.000547

Copyright@ Gadelkareem RA, This article is distributed under the terms of the Creative Commons Attribution 4.0 International License, which permits unrestricted use and redistribution provided that the original author and source are credited.

\section{Gadelkareem RA* and Elgammal MA}

Assiut Urology and Nephrology Hospital, Faculty of Medicine, Assiut University, Assiut, Egypt

\section{Abstract}

Aposthia or natural circumcision is a very rare preputial anomaly that should be differentiated from hypospadias. Here, we report on a 3-day-old male neonate who presented with a congenitally deficient prepuce and normal development of the urethra and external urethral meatus. Physical examination and abdominal ultrasonography revealed no other abnormalities. Relatives were assured about the anomaly, where no further interventions were needed.

Keywords: Aposthia; Hypospadias; Natural circumcision; Prepuce

\section{Case Description}

A 3-day-old male neonate presented with his grandfather to our urology clinic for an anomalous prepuce. Parents were instructed to consult a urologist for the nature of the anomaly. The baby was full term with $3.5 \mathrm{~kg}$ birth weight and unremarkable other findings, breast-feed, and started regular urinary voiding. Local examination revealed normal sized and positioned testis in each hemiscrotum with bilateral mild hydroceles. The penis was normal in length without curvatures. However, the prepuce was deficient all around and covered only less than the half of the glans penis. The external urethral meatus was slit-like and normally positioned but was relatively wide (Figures 1 \& 2). Abdominal ultrasonography revealed no urinary abnormalities. Relatives were assured as there were no needed further interventions. Accordingly, we should declare the differences between a deficient prepuce without hypospadias which is known as aposthia and a hypospadias with ventrally abnormal meatus and ventrally deficient prepuce. While the latter anomaly is relatively common, the former one is very rare and is known as aposthia, microposthia or natural circumcision [1]. Different postulations have been proposed for its explanation up to familial and abnormal genetic expression hypothesis [2].

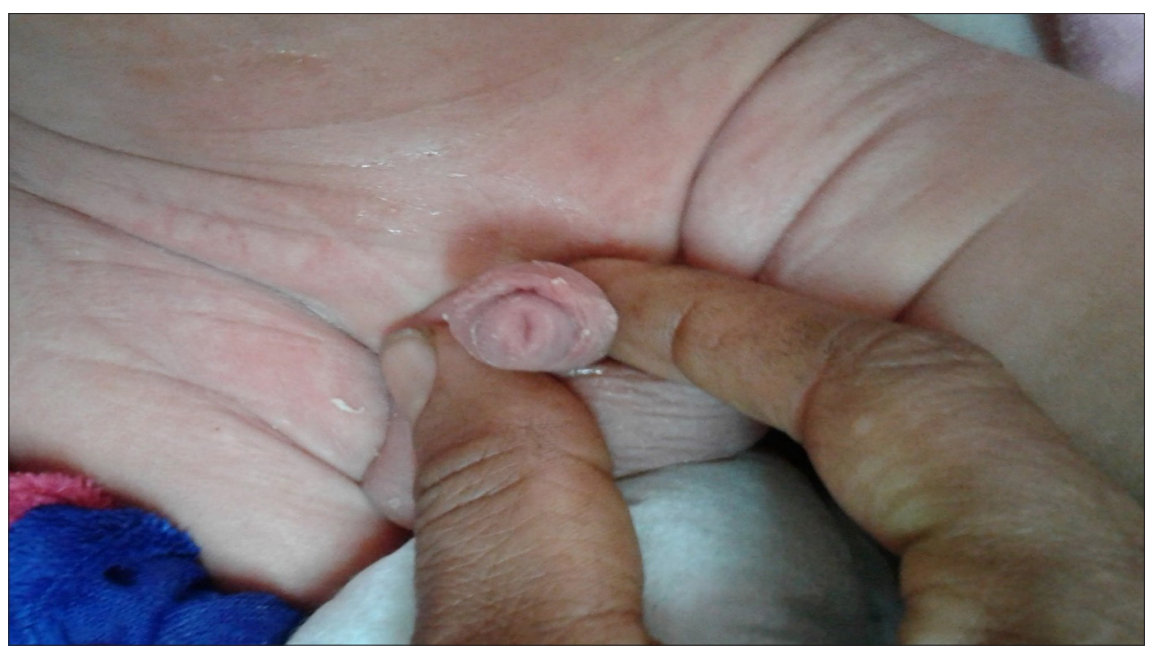

Figure 1: View of the deficient prepuce while the penis is supported. Note the relatively wide urethral meatus. 


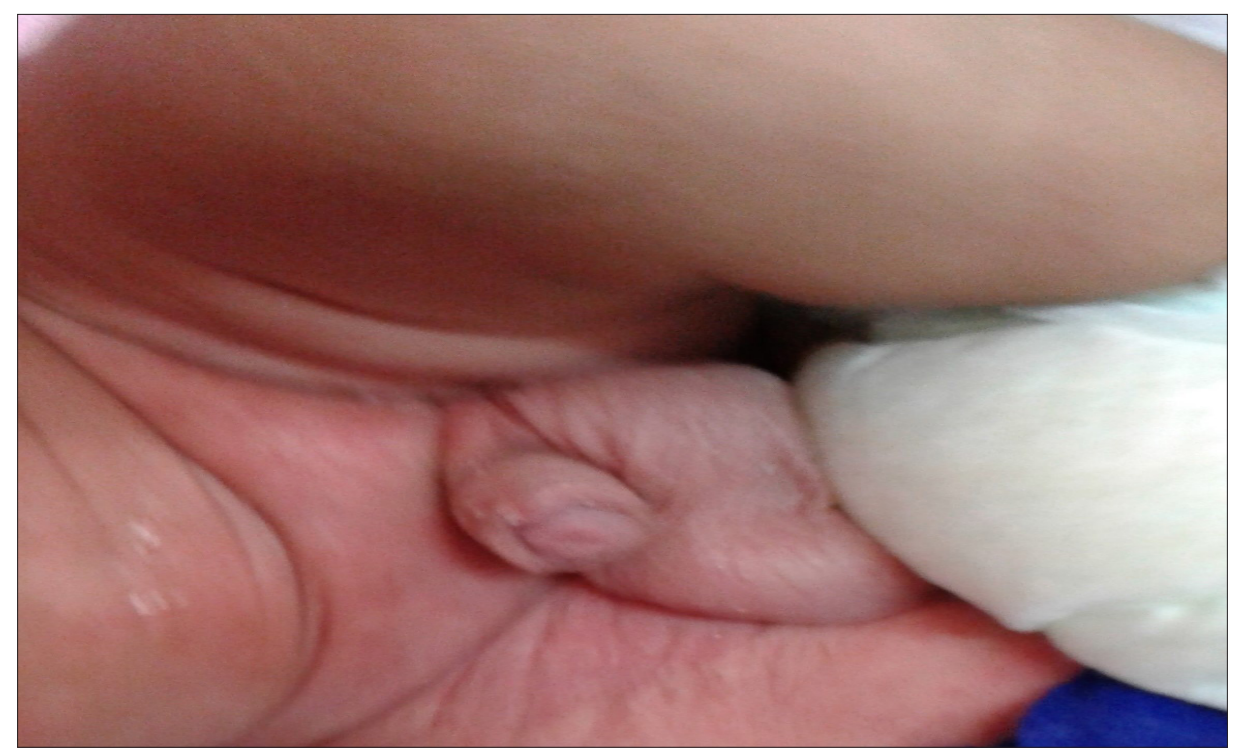

Figure 2: A confirmatory view of the deficient prepuce while the penis is unsupported.

\section{Conclusion}

Aposthia is a very rare condition of congenitally deficient prepuce without hypospadias. It is a spot diagnosis and usually needs no interventions other than assurance of the parents.

\section{References}

1. Palacios GM, Gallart MR, Barca RP, Martinez EE, Casasnovas BA (2013) Congenital absence of preputial foreskin: An extremely uncommon anomaly. J Pediatr Surg 48(2): e13-e15.
2. Din AUM, Salam A, Rafiq MA, Khaliq I, Ansar M, et al. (2007) Aposthia: a birth defect or normal quantitative recessive human genetic trait? East Mediterr Health J 13(2): 280-286. 